\title{
The Effect of Fluency Oriented Reading Instructionon EFL Students'Reading Fluency and Comprehension
}

\begin{abstract}
:
This paper discusses and examines the effects of a fluency reading instruction cycle onstudents' progress in there ading skill. To reach this objective, the study implemented the Fluency Oriented Reading Instruction (FORI) approach, a research-based integrated fluency routine framework, to determine if the components of reading fluency (automaticity, word recognition accuracy, prosody, and comprehension) improve. The present research was conductedatthe department of English in the ENS-C where an experimental pretest-posttest with control group design was used. Pretest and posttests of reading fluency, reading comprehension and reading prosody were administered, and a $t$ test was used to compare the means of correct word per minute (CWPM), prosody, and comprehension within an experimental group and a control group. The results indicated that the FORI is an effective approach to improve students'reading fluency and comprehension as demonstrated by CWPM improvement, prosody gains, and comprehension achievements as well.

Key words: Fluency Oriented Reading Instruction (FORI), Reading Fluency (RF), Automaticity, Reading Prosody, Correct Word Per Minute (CWPM), Reading Comprehension $(R C)$

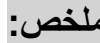

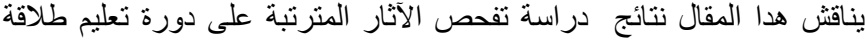

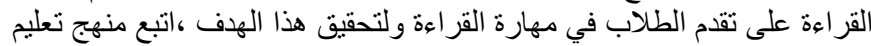

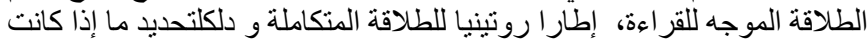

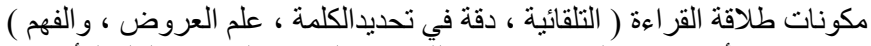
قد تحسنت ـ أجري هذا البحث في قسم اللغة الإنجليزية فيالمدرسة العلية العيا للأساتذة،

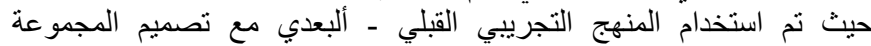

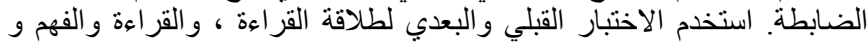

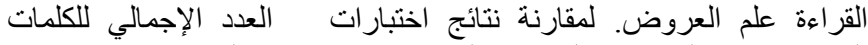

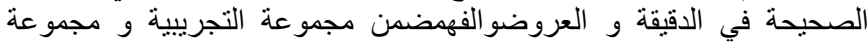
ضابطة و تم تحليلها عن طريق اختبار إحصائي(a

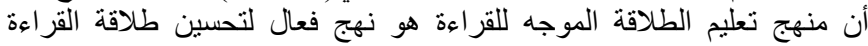
والاستيعاب لدى الطلاب من خلال تحسن عدد الكلمات الكات الصحيحة في الدقيقة،

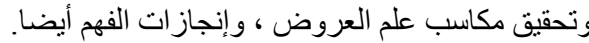

\section{BOUGUEBS Radia}

Faculty of Letters and Languages Department of Foreign Languages University of Mentouri Constantine

\begin{abstract}
Introduction:
Remarkable achievements in the field of fluency development in L1 context provided many implications for ESL/EFL reading and instruction (Grab, 2010).

Since then, foreign language practitioners'

debateshaveshifted towards readingfluency, especially after determining that fluent reading is the key indicator of
\end{abstract}


L2 highly skilled readers(Grab,2010:72). Though EFL studies investigating this fieldare limited, Nation's (2014) continuous writing for more than two decades about the importance of developing fluency in ESL/EFL context inspired few researchers to dig deep in this area. Some preliminary studies have directed the attention to the fundamental role thatreading fluency may have on successful reading comprehension (Day \&Bamford, 1998; Taguchi \&Gorsuch, 2002; Takayasu-Maass\&Gorsuch, 2004) as opposed to just considering fluency a byproduct of reading skills(Taguchi et al., 2006). Identified as an indicator of reading competence, developingEFL students' reading fluencyhasbecomea prerequisite (Nation, 2009; Grab, 2010). Becausestudents, or teachertrainees,inthe ENS-C study reading techniques, as an independent subject, during the first two years of the training,weassumethat the more their reading fluency is in continuous check, the better their fluent reading will be.

\section{Defining Reading Fluency}

Generally, fluency is the ability to make the best use of what is already known (Nation, 2009). In oral reading, it is demonstrated through an effortless reading where the reader's ability goes beyond recognizing words quickly in the text to reading and using expression manifesting his appropriate understanding of what is read. Reading fluency, then, combines accuracy, automaticity, and oral reading prosody which, taken together, contribute toan effective comprehension and overall good reading(Kuhn et al., 2010).

\section{Components of Reading Fluency}

The first component of fluency is referred to asAutomaticity. Itis the ability to decode words withless conscious attention both accurately and rapidly (Samuels, 1979).Accuracyis the capacity to recognize and decode words correctly in a text facilitatingthe reader's understanding and correct interpretation of what is being read (Hudson et al., 2005). It is recognized as a precondition for fluency; however, it can never stand alone as a predictor of a fluent reading unless the recognition of words is processed rapidly(Kuhn \& Stahl, 2003). Speed is the ability to read at a conversational rate. Itis both a characteristic of a fluent reading and a prerequisite for good comprehension to occur (Hudson et al., 2005).

Besides automaticity, prosodystands as the second pillar of reading fluency. Itrefers to the ability to project tonal aspects of speech on to print making the reader's reading soundnatural as if $\mathrm{s} / \mathrm{he}$ is speaking. The prosodic reading implies the compilation of the spoken language features including stress or emphasis, pitch variations, intonation, rate, pausing and other elements in oral expression (Osborn \& Lehr, 2003).

Comprehension, in a fluent reading, is possibleaccording to Samuels (2002). This occurs when many components of the reading process coordinate; starting by the recognition of the word, accessing word meaning, deciding on the correct meaning of the word, grouping words into grammatical units, 


\section{The Effect of Fluency Oriented Reading Instructionon \\ EFL Students'Reading Fluency and Comprehension}

generating inferences, using reader knowledge to construct coherent, understandable model of the text. In brief, the construction of meaning in the text, which is an ultimate goal in the reading process, is made possible; unless, few of the above listed components are to be executed automatically.

\section{Reading Fluency and Automaticity Theory}

Reading is a complex process requiring both decoding and comprehending what has been decoded. Bothtasks demand a cognitive attentionfrom the part of the reader that may exceed his/her limited cognitive capacity. As reading is for comprehending, for a successful comprehension to occur, the reader should go beyond accuracy to automaticity in decoding (Samuels, 1976:323). Suchan assertion is supported by the LaBerge and Samuels' Automaticity Theory (1974). For a successful comprehension to occur, the decoding task should be carried out automatically. In that, the reader has to recognize words with almost no attention because his full cognitive attention is concentrated on the comprehension task. Furthermore, when achieving automaticity, argues Rasinski (2003), the reader's cognitive capacity is not only shifted to the comprehension, but also to giving sense to the text. This is achieved through the expressive interpretation of what is read. The latter is manifested via the reader's ability to embed appropriate volume, tone, phrasing and other elements in oral expression that give evidence that the reader is actively constructing meaning from the passage.

\section{Reading Fluency in Foreign Language Context}

As the cognitive processes (decodingand understanding) involved in a fluent reading are the same for both L1 and L2/FL readers(Day \&Bamford, 1998), developing reading fluency becomes a prerequisite not only for L1 readers (NRP, 2000;Samuels,2002), but alsofor SL/FL readers too (Day \&Bamford, 1998; Nation, 2009). By developing the automatic word recognition skills of either L1 or L2/FL, students can devote the unused portion of their cognitive attention to a higher cognitive processing on which understanding is based. Developing automaticity in reading as a stepping stone for facilitating generating meaning from a print urges researchers and educators to look for the appropriate fluency instructions that foster reading fluency main components: automaticity, prosody, and comprehension.

\section{Reading Fluency Instruction}

Researchers in the field of fluency development conclude that instead of letting this skill develop by itself as being "a logical outcome of literacy" where the consequence may be positive or negative, it would be better if fluency instructions are embedded in all reading instructional programs right from the beginning of learning to read (Samuels, 1979; Samuels, 2002; Nation, 2009).

The LaBerge and Samuels's automaticity theory (1974) which provides only the theoretical foundation for developing reading fluency has encouraged researchers to develop new methods that follow the teaching implications of 
thistheory. It wasstated that an elevated level of automaticity is achieved as a result of iterative cycles of reading.In 1976 Chomsky set a method which she referred to as Tape Assisted Reading Method. Regarded as a pioneer, Samuels put into practice the Automaticity theory. However, the new developed method (Repeated Reading) was not published till the year of 1979.In Samuels' Repeated Reading method students are encouraged to read passages out loud repeatedly with systematic and explicit guidance and feedback from their teacher.Different from Samuels, Chomsky used a tape-recorded model of reading instead of using a live model reading.Currently, there are many variations of the repeated reading method such as: Student-Adult Reading(Clark, 1995), Choral Reading (Willis, 2008), Partner Reading (Vaughn et al., 2000; Meisinger et al., 2004), Readers' Theatre(Rasinski, 2003), Echo Reading (Hapstak\& Tracey, 2007) .

\section{FORI: Integrated Fluency Instructional routine}

Integrated fluency instructional routines are fluency lessons where a multiple number of effective fluency instruction including repeated reading method, partner reading choral reading...etc. is followed daily in a week cycle. These routines as Oral Recitation Lessons (ORL), Fluency Development Lessons(FDL), and Fluency Oriented Reading Instruction (FORI)can be used in whole class and small group settings as well.(Schwanenflugel, 2008; Thornton, 2008)

Hoffman's (1987) ORL is a framework where a basal reading lesson over the course of a week is effectively implemented (Kuhn et al., 2006). After selecting a reading material that lends itself to performance, an ORL starts (Nichols et al., 2008). The structure of the ORL requires teacher'smodeling of a fluent oral reading,followed by a comprehension focus,andthenstudentsengage in fluency practice strategies while reading the story either alone or with a partner. The cycle ends with student's performance of the story.FDL is a kind of fluency lesson which follows a similar format as the ORL with the exception that Rasinski et al. (1994) combined an oral recitation lesson and paired repeated reading where they used short texts such poems, rhymes, songs, story segments, short passages instead of stories (Kuhn et al., 2006).

The FORIroutinewasdesigned for wide classroom instruction by Stahl \&Heubach(2005). Its initial goalis the provision of heavily scaffolded reading instruction to ensurethat students have multiple opportunities to read each selection. The FORI procedure calls for a weekly format that incorporates echo, choral, and partner reading into a systematic lesson plan involving the teaching of a single challenging connected text selected from basal reading over a five-day period. Besides developing students' reading fluency, from the first session of the week till the last one, the teacher uses some comprehension strategies that foster students' comprehension of the text through class 
discussion, vocabulary study, story map or graphic organizer, and extension activities in the form of written or oral responses to the week's selection. The aim from these activities is to emphasize that the primary goal of FORI is text comprehension.

\section{Relationship between Reading Fluency and FORI}

Researchers suggest that reading fluency improves not only by multiplying the readers' opportunities to practice reading connected text (Repeated Reading Strategies) but also by scaffolding practice heavily. Byproviding sufficient instructional support in the form of immediate feedback and modeling, students are allowed to experience automatic and expressive reading (Kuhn \& Stahl, 2003; Samuels, 2002). As FORI framework incorporates an extensive support or scaffolding as part of its overall lesson plan, students gain benefits from the in-class reading instruction. The effectiveness of this integrated instructional routine as a key to fluency progress, Kuhn \&Deborah argue(2008: 32)is due to the use of scaffolded support and the focus on extensive oral reading of more difficult texts during instruction.

Our purpose, in this study, is to investigate the effect of FORI on reading fluency and comprehension of second year EFL students at the Teacher Training School of Constantine. In the scope of this research, operational definitions are giventothe following terms:

a) In the current work, we use an adaptation of Stahl \&Heubach'sFORI (2005). However, we limit the number of contact days to three days instead of five; but we increase the duration of each session from 20 minutes to 30 minutes. This cycle includes the following steps: (1) Modeling, text comprehension, a review of the key vocabulary, and the teacher leads /or Echoic reading; (2) Partner rereading of the text; (3) Choral reading practice plus extension activities that focus on comprehension.

b) Reading Fluency (RF) which refers to the ability to read orally with accuracy, with an appropriate speed and with a proper expression is measured by the number of words read correctly in one minute (CWPM).

c) Reading prosodyis rated through Multi Dimensional Fluency Scale rubric (Zutell\&Rasinki, 1991). This rubric enables the teacher to rate (1) reader's expression and volume, (2)phrasing, (3)smoothness, and(4) pace.

d) Reading Comprehension ( $\mathrm{RC}$ ) is measured via comprehension retelling question which requires the recall of information that is contained in idea units of the text read (Fuchs et al, 2001).

8. The Study 
To investigate whether the implementation of theFORI method enhances CWPM, prosody and reading comprehension scores of second year EFL teacher-traineesat ENS-C,we are guided by the following research questions:

1. Does the use of FORI result in a statistically significant difference in secondyear EFL learners' CWPM?

2. Does the use of FORI result in a statistically significant difference in secondyear EFL learners' Prosody?

3. Does the use of FORI result in a statistically significant difference in secondyear EFL learners'comprehension?

The research questions may be answered if the study examinesthe effects ofafluency instructional approach,FORI, on reading fluency and reading comprehension development. Therefore, three hypotheses are formulated below:

1. When the Fluency Oriented Reading Instruction is applied, it will enhance second year EFL learnersreading automaticity.

2. When the Fluency Oriented Reading Instruction is applied, it will enhance second year EFL learnersreading prosody.

3. When the Fluency Oriented Reading Instruction is applied, it will enhance second year EFL learnersreading comprehension.

\subsection{Method and Instrumentation}

As this research worktook place in pre-existing educational settings, whereindividual students were not randomly assignedto the control or experimentalcondition, a quasi-experimentalstudywas carried out on a sample of population selected from second year students.TheReading Technique Module is taught to first and secondyear students. During their first year, they are just introduced to the different reading strategies. Since theFORI training requiresstudents who manipulate the different comprehension strategies, second year students represent the target. Sixty (60) students represented the total number of the participants wherethirty (30) of them represent to the experimental group and the other thirty (30) students serve as the control group.

Thecurrent study was conductedover nine (09) weeks. Prior to the experiment, the participants were pre-tested through Three Minutes Reading Assessment: Word Recognition, Fluency and Comprehension test (Rasinski\&Pedak, 2005)to know consecutively their reading fluency scores, prosody scores, and comprehension retelling scores as well. From October to December2015, over a nine (09) week study, three (03) times a week and (30) minutes per session, the experimental group followed the FORI instruction, and the control group (CG)received the ordinary reading instruction.As the FORI cycle is incomplete without at home reading activities, the participants spent at least fifteen minutes at homeforextra reading. Each participant, during the week, was required to read a short story of his own choice of about eight to ten 


\section{The Effect of Fluency Oriented Reading Instructionon \\ EFL Students'Reading Fluency and Comprehension}

pages and respond to it in his reading response journal through which the teacher supervised this activity. At the end of the experiment, the participants were post-tested via the same test used in the pre-test.

\subsection{Analysis of the Results}

The collected data of both pre and post tests are analyzed in this section. The latter is divided into two parts: first, the results of each dependent variable during the posttest are demonstrated in graphs to visualize if there is an apparent difference in the performance of the two groups (FORI-G and CG). In the second part, and after describing statistically the collected data from the pre-test and the posttest of the three dependent variables, CWPM, Prosody and $\mathrm{RC}$,we compare means. As long as a hypothesis cannot be confirmed just by comparing means, mainly if the difference is not large, a quantitative analysis is followed.We have used a $t$-test analysis to show the results' validity andreinforce the drawn conclusions.

Research Question 1:Does the use of FORI result in a statistically significant difference in $2^{\text {nd }}$ year EFL learners CWPM?

Figure1shows that theblue curve representing the performance of the FORI-G in the posttest is slightly superior to that of CG, the red curve. But still, we cannot build upon visual perception solid conclusions.

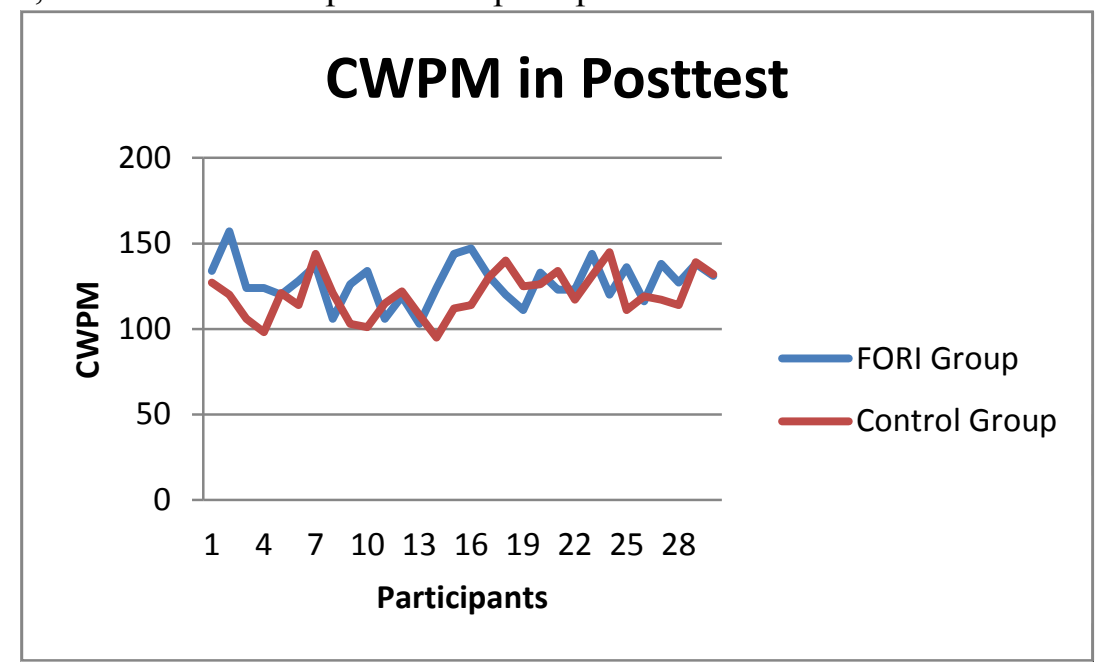

\section{Comparing the Means}

Figure1

From the results listed onTable1, we notice remarkable differences in SD, Median, Min, Max scores that distinguish the FORI-G from the CG in the posttest. Despite the fact that the difference between the means of the two groups is somehow inconsiderable (only 1 CWPM) in the pre-test; this difference, however, increases to reach 7.4333 CWPM by the end of the study. This reveals that the FORI-G manifests a progress in reading fluency which is 
not the case of the CG whose reading fluency scores have rather regressed since the pre-test.

\begin{tabular}{|l|c|c|c|c|}
\hline \multirow{2}{*}{$\begin{array}{c}\text { Descriptive } \\
\text { Statistics }\end{array}$} & \multicolumn{2}{|c|}{ CG } & \multicolumn{2}{c|}{ FORI-G } \\
\cline { 2 - 5 } & Pretest & Posttest & Pretest & Posttest \\
\hline N & 30 & 30 & 30 & 30 \\
\hline Mean & 124,2 & 120.03 & 123.2 & 127.46 \\
\hline SD & 12.793 & 13.176 & 9.341 & 12.549 \\
\hline Median & 125.50 & 119.50 & 124.50 & 126.50 \\
\hline MIN & 94 & 95 & 105 & 103 \\
\hline MAX & 145 & 145 & 140 & 157 \\
\hline
\end{tabular}

Table1: CWPM in the Pre and Posttest

t-Test Analysis

Since this work is based on one tailed test, to confirm or refutethe stated hypothesis, the calculated $t$ at 0,05 level of significance must equal or exceedthe half of the critical $t$. The results from Independent Samples t-test Procedure reveal that the calculated $t$ with 58 degrees of freedom at 0,05 level of significance equals 2,237. Since the value of the calculated $t$ exceeds the value of the critical t 2,237 >1,000, this means that the results obtained from this study are statistically different. Consequently, a statistically-significant difference exists between the two groups in terms of CWPM. Such a conclusion reflects the positive effect of the FORI procedure to which the experimental group has been exposed. The research questionasserting that when FORI is applied, second year EFL learners' CWPM increase is upheld.

Research Question Two:Does the use of FORI result in a statistically significant difference in second year EFL learners reading prosody?

Figure2,below, shows that the performance of the FORI-G in the posttest as represented by the blue line is considerably increasing from that of the $\mathrm{CG}$ which is represented by the red line. 


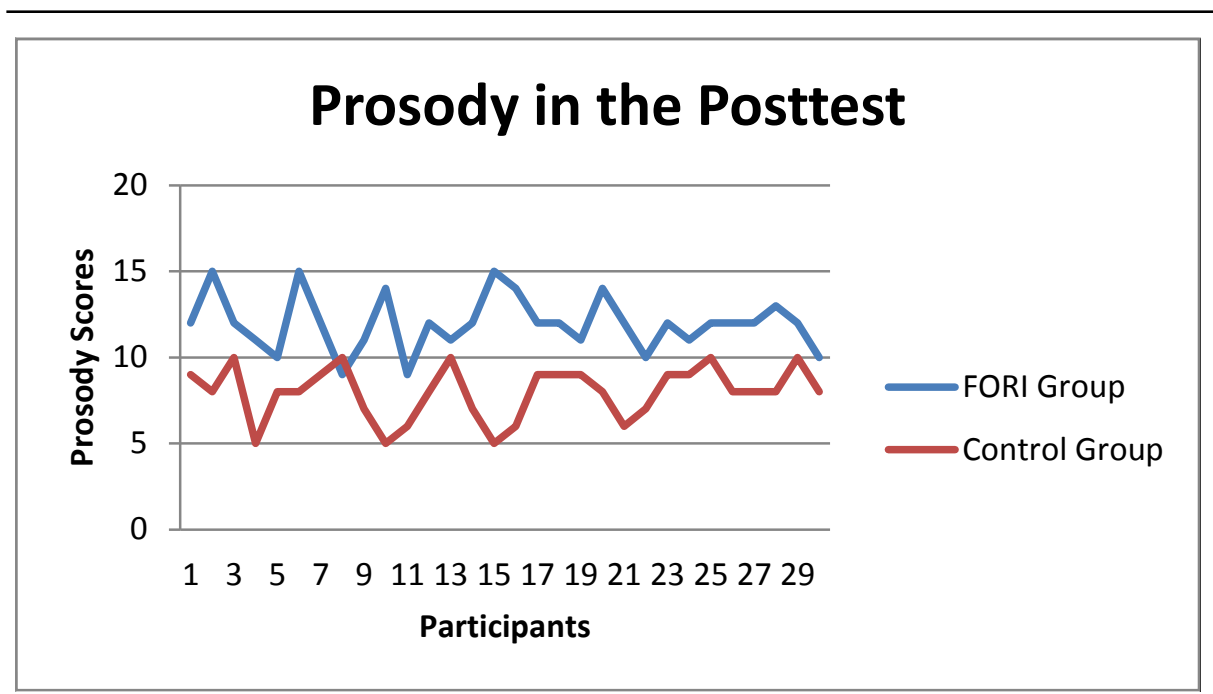

\section{Comparing Means}

Figure2

By glimpsing atthe results of Table2, we notice remarkable differences in the Mean, SD, Median, Min, and Max scores between the FORI-G and CG from the pre-test to the posttest. Notwithstanding the negligible difference between the means of the two groups in the pretest (only 0.1), there is a remarkable increase that reaches 4 in the posttest. This affirms that the FORI-G shows perceptible progress in prosody which is not the case of the CG.

\begin{tabular}{|l|c|c|c|c|}
\hline \multirow{2}{*}{$\begin{array}{c}\text { Descriptive } \\
\text { Statistics }\end{array}$} & \multicolumn{2}{|c|}{ CG } & \multicolumn{2}{c|}{ FORI-G } \\
\cline { 2 - 5 } & Pretest & Posttest & Pretest & Posttest \\
\hline N & 30 & 30 & 30 & 30 \\
\hline Mean & 8.93 & 7.97 & 9.03 & 11.97 \\
\hline SD & 1.574 & 1.542 & 1.450 & 1.608 \\
\hline Median & 9 & 8 & 9 & 12 \\
\hline MIN & 6 & 5 & 5 & 9 \\
\hline MAX & 12 & 11 & 11 & 15 \\
\hline
\end{tabular}

Table 2: Prosody in Pre and Posttest

t-Test analysis:

The results from Independent Samples t-test Procedurereport that the calculated $t$ at 0,05 level of significance equals 9,834 . Since the value of the calculated $t$ exceeds the value of the critical $\mathrm{t} 9,834>1,000$, this means that 
the results obtained from this study are statistically different. We can be at $95 \%$ confidence that the difference between the mean scores of prosody of the two groups is statistically significant. Such a conclusion manifests the positive effect of the FORI procedure on prosody to which the experimental group has been exposed. The research question asking whether the use of the FORI results in a statistically-significantincreasein second year EFL learners' prosody is answered positively.

Research Question Three:Does the use of FORI result in a statistically significant difference in second year EFL learners reading comprehension?

In Figure 3, the blue line clearly shows that the performance of the FORI group in the posttest is noticeable as compared to the red line representing the performance of the CG.

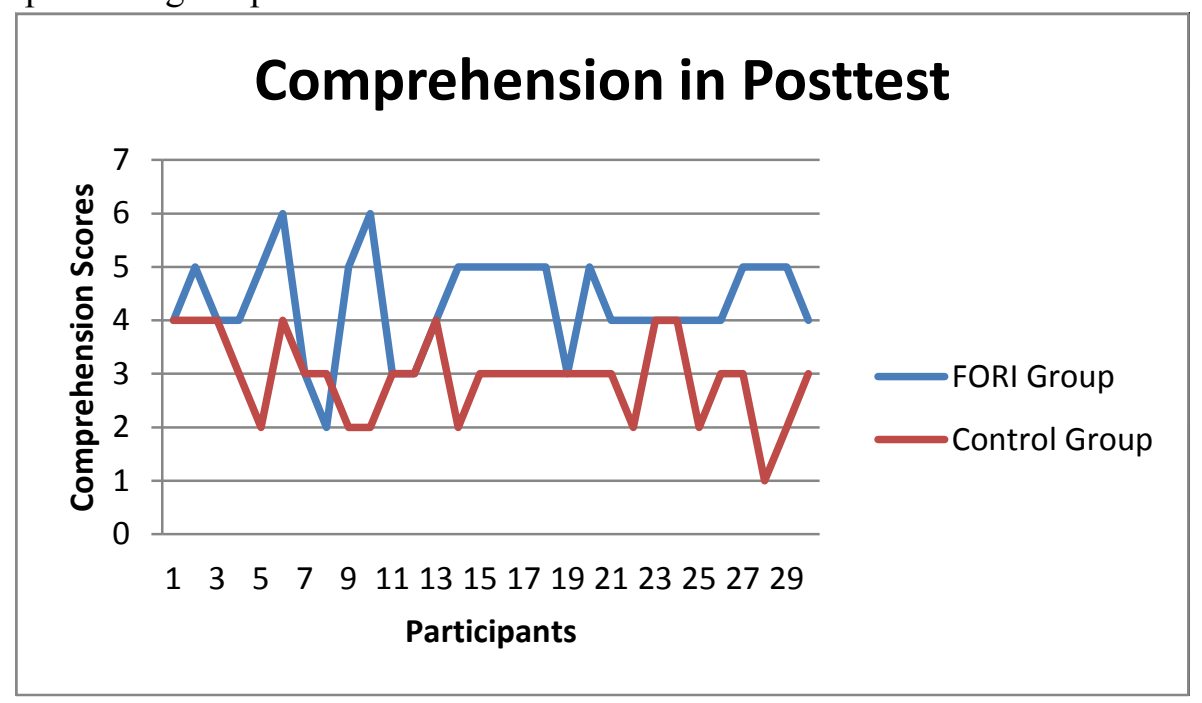

\section{Comparing Means}

Figure 3

When comparing pre-test and post-test comprehension rating scores between the FORI-G and the CG, we notice that the mean score of the control group in the pre-test is 2,93 and the mean score in the posttest is 2,67. The FORI-G, however, manifests an increase in the comprehension achievement that equals $+1,33$ between the pretest and the posttest. Besides the differences in the means, we notice remarkable differences in SD, Median, Min, Maxscores. Table 3 sums up the above discussed data. 
The Effect of Fluency Oriented Reading Instructionon

EFL Students'Reading Fluency and Comprehension

\begin{tabular}{|l|c|c|c|c|}
\hline \multirow{2}{*}{$\begin{array}{c}\text { Descriptive } \\
\text { Statistics }\end{array}$} & \multicolumn{2}{c|}{ CG } & \multicolumn{2}{c|}{ FORI-G } \\
\cline { 2 - 5 } & Pretest & Posttest & Pretest & Posttest \\
\hline N & 30 & 30 & 30 & 30 \\
\hline Mean & 2,67 & 2.93 & 3.00 & 4.33 \\
\hline SD & .711 & .785 & .643 & .922 \\
\hline Median & 3 & 3 & 3 & 4 \\
\hline MIN & 1 & 1 & 2 & 2 \\
\hline MAX & 3 & 4 & 4 & 6 \\
\hline
\end{tabular}

Table 3: RC in Pre and Posttest

t-Test analysis

The results from Independent Samples t-test Procedure divulge that the calculated $t$ at 0,05 level of significance equals 6,332. Since the value of the calculated $t$ exceeds the value of the critical $\mathrm{t} 6,332>1,000$, the results obtained from this study are statistically different. Such conclusion reflects the positive effect of the FORI procedure on comprehension to which the experimental group has been exposed. Theresearch question stating that when the FORI is applied, second year EFL learners' comprehensionenhanceis proved true.

\subsection{Discussion}

The purpose of this study was to examine the effect of an integrated fluency routine on reading fluency and comprehension. We opted, then, for an adaptation of Fluency Oriented Reading Instruction approach (Stahl \&Heubach, 2005), a widely research-based fluency instruction framework, to study its significance in improving reading fluency and comprehension of second year EFL teacher-traineesat ENS-C.

During the pre-test, both the FORI group and the control group performedroughlyinthe same way.The differences in CWPM, Prosody and comprehension are somehow negligible. However in the posttest, noticeable differences are diagnosed in the three dependent variables. The FORI-G reading fluency as measured by the number of words read correctly in one minute (CWPM) increases as compared to the CG reading fluency CWPM. The striking finding concerns word reading accuracy. The FORI-G reads at $97 \%$ word accuracy during the posttest, and the CG reading accuracy reaches 94\%. Such findings confirm previous studies suggesting that effective fluency instruction enhances readers' accurate recognition of words (Samuels, 1976, 1979, 2002; Rasinski, 2004; Tagushi et al., 2006). Similar remarkable progress paints the FORI-G reading prosody performance in the posttest where participants manifest a growth in the four components of prosody: expression and volume, phrasing and intonation, smoothness, and pace. Such results go in parallel with previous researches claiming that a fluent oral reading sounds 
much like speech with appropriate phrasing, pause structures, stress, rise and fall patterns, and general expressiveness(Schwanenflugel et al., 2004; Kuhn et al., 2006 ). Gains in comprehension crown the results of the FORI-G. The latter manifests an increase in the ability to comprehend more than the CG.

These conclusions suggest that the regular use of the FORI results in a significant statistical improvement in CWPM, prosody, and comprehension retelling. It is never chance and randomness which lead to such positive effects in the posttest; comparatively, this is consistent with the findings of Stahl \&Heubach(2005),Torthon (2008) and Kuhn et al. (2006) researches. In these studies, FORI training proved to be effective in developing L1 reading fluency, prosody and comprehension. The FORI approach that incorporates instructional strategies such as Repeated Reading, Choral Reading, and Partner Reading is proved to be effective in developing reading fluency and comprehension (Rasinski, 2004; Stahl \&Heubach, 2005, Kuhn et al., 2010).This approachis confirmed to be effective as a whole class fluency instructional routine in L1 contexts(Kuhn \& Deborah, 2008)andhas the same effect in EFL contexts too.

\section{Conclusion}

This paper describes a nine-week quasi-experimental FORI study carried out with second year EFL students at ENS-C using a Three Minutes Reading Assessment: Word Recognition, Fluency and Comprehension test. Findings revealed that FORI was efficient in increasing reading fluency and comprehension of the experimental group as compared with the CG which does not follow any reading treatment. We conclude that the implementation of instructional practices that involve classroom routines and strategies such as the FORI can help in enhancing reading fluency as it provides explicit instruction that focuses simultaneously on accuracy, automaticity, and prosody; however, the main benefit a reader under this instructional classroom setting can gain is comprehension.EFL learners can reach a level of expertise in reading fluency crowned by comprehension if the FORI is part of their reading programme.

\section{References}

1. Clark, C. H. (1995). Teaching Students about Reading: A Fluency Example. Reading Horizons, Vol 35, No.3, 250-266.

2. Day,R.R\&Bamford,J.(1998).Extensive Reading in the Second language Classroom. Cambridge University Press.

3. Fuchs, L.S, D. Fuchs, M.K Hosp and J. Jenkins. (2001). Oral Reading Fluency as an Indicator of Reading Competence: Theoretical Empirical and Historical Analysis. Scientific Studies of Reading, vol 5, $\mathrm{n}^{\circ} 3$, (239-256), Lawrence Arlbaum Associates.

4. Grab, W.(2004).Research on Teaching Reading.Annual Review of Applied Linguistics. Cambridge University Press, (44-69) 
5. Grab, W.(2010). Fluency in reading-Thirty-five years later. Reading in a Foreign Language Volume 22, No. 1, (71-83)

6. Hapstak, J. A. \& Tracey, D. H. (2007). Effects of Assisted Repeated Reading on Students of Varying Reading Ability: a Single Subject Experimental Research Study. Reading Horizons Journal, Vol 47, No.4, 315-334.

7. Hudson, R.F, Pullen C.P and Lane, H.B.(2005). Reading Fluency Assessment and Instruction: What, Why and How? TheInternational Reading Association. (702-714)

8. Kuhn, M.R \& Stahl, S.A. (2003). Fluency: A Review of Developmental and Remedial Practices. Journal of Educational Psychology. Vol 95, Issue 1, (3-21)

9. Kuhn, M.R, P.G Schwanenflugel, R.D Morris, L.M Morrow, D.G Woo, E.B Meisenger, R.A Savcik, B.A Bradley and S.A Stahl.(2006).Teaching Children to Become Fluent and Automatic Readers. Journal of Literacy Research. Vol 38, $\mathrm{n}^{\circ} 4$, (357-387), Lawrence Erlbaum Associates.

10. Kuhn, M.R, P.G Schwanenflugel.(2006). All Oral Reading Practice Is not Equal or How Can I Integrate Fluency into my Classroom. Literacy Teaching and Learning. Vol 11, $\mathrm{n}^{\circ} 1,(1-20)$

11. Kuhn, M.R, G.W Deborah.(2008). Fluency-Oriented Reading Instruction:TwoWhole Classroom Approaches.The Guilford Press, Chapter 2, (17-35)

12. Kuhn, M.R, P.G Schwanenflugel and E.B Meisenger. (2010). Aligning Theory and Assessment of Reading Fluency: Automaticity, Prosody and Definitions of Fluency. Reading Research Quarterly, vol 45, $\mathrm{n}^{\circ} 2$, (230-251).

13. Meisinger, E. B, Schwanenflugel, P. J, Bradely, B. A. \&Stahl, S. (2004). Interaction Quality during Partner Reading. Journal of Literacy Research, Vol 36, No. 2, 111-140.

14. National Reading Panel (2000). Teaching Children to Read: An Evidence Based Assessment of the Scientific Research Literature on Reading and its Implications for Reading Instruction. Washington D.C. National Institute of Child Health and Human Development.

15. Nation,I.S.P.(2009).Teaching EFL/ESL Reading and Writing. Routlege, Taylor \&Francis

16. Nation,P. (2014). Developing Fluency. In Muller, T, Adamson, J, Brown, P.S, Herder, S \& Basin stoke (eds), Exploring EFL Fluency in Asia. Palgrave Macmillan .Chapter 1, 11-25.

17. Nichols, W.D, W.H Rupley\& T. Rasinski. (2008). Fluency in Learning to Read for Meaning: Going Beyond Repeated Readings. Literacy Research and Instruction, $\mathrm{Vol} 48, \mathrm{n}^{\circ} 1, \mathrm{pp}(1-13)$ 
18. Osborn, J, F Lehr \& E.H Hiebert (2003). A Focus on Fluency. Pacific Resources for Education and Learning.

19. Rasinski, T. (2003). The Fluent Reader: Oral Reading Strategies for Building Word Recognition, Fluency, and Comprehension. Teaching Resources/ Scholastics

20. Rasinski, T. (2004). Assessing Reading Fluency. Pacific Resources for Education and Learning. Honolulu. Hawaii.

21. Rasinski T, Pedak, N. (2005). Three Minutes Reading Assessment: Word Recognition, Fluency and Comprehension. Scholastic Teaching Resources.

22. Samuels,S.J.(1976). Automatic Decoding and Reading Comprehension. Language Arts, vol 53, $\mathrm{n}^{\circ}$ 3, (323-325)

23. Samuels,S.J.(1979). How The Mind Works When Reading:Describing Elephants No One Has Ever Seen. In The Theory and Practice of Early Reading-Volume I-, Weaver, P A and Resnick L.B (eds). Lawrence Erlbaum Associates. Chapter: 14, (343-368)

24. Samuels, S.J. (2002). Reading Fluency: Its Development and Assessment.InWhat Research Has to Say about Fluency Instruction, S.J, Samuels and A.E, Farstrup (eds). International Reading Association. $3^{\text {rd }}$ edition, Chapter 8, (166-183).

25. Stahl, S.A, K.M Heubach. (2005). Fluency Oriented Reading Instruction. Journal of LitracyResearch, vol 37, $\mathrm{n}^{\circ} 1,(25-60)$.

26. Schwanenflugel, P.(2008). Fluency Development and Whole Class Instruction: Approaches for Shared Reading.The Guilford Press, chapter 3, (.41- 77).

27. Taguchi, E. \&Gorsuch, G. J. (2002). Transfer Effects of Repeated EFL Reading on Reading New Passages: A Preliminary Investigation. Reading in a Foreign Language, Vol: 14, $\mathrm{n}^{\circ}(1),(43-65)$.

28. Taguchi, E, Gorsuch, G. J \&Takayasu-Maass, M. (2004). Developing Reading Fluency in EFL: How Assisted Repeated Reading and Extensive Reading Affect Fluency Development. Reading in a Foreign Language. vol 16, $\mathrm{n}^{\circ} 2$, (70-96).

29. Taguchi, E,Gorsuch, G. J \&Sasamoto, E. (2006). Developing Second and Foreign Language Reading Fluency and its Effect on Comprehension. The Reading Matrix, Vol. 6, No.2.

30. Willis, J. (2008). Teaching the Brain to Read: Strategies for Improving Fluency, Vocabulary, and Comprehension. Association for Supervision and Curriculum Development (ASCD).

\section{Dissertations}

1. Thornton, P.G. (2008). Effect of Modified Fluency-Oriented Reading Instruction on African American Boys' Oral Reading Fluency and 
The Effect of Fluency Oriented Reading Instructionon

EFL Students'Reading Fluency and Comprehension

Attitude towards Reading. (published PHD thesis). Faculty of Auburn University. 